\title{
Генезис этических норм в цифровой среде как фактор аномии личности представителей поколения $\mathrm{Z}$
}

\author{
А.В. Плетнев \\ Санкт-Петербургский университет МВД России \\ Venger.vin@Rambler.ru
}

\section{Аннотация}

Социализация представителей поколения $\mathrm{Z}$ в значительной мере происходит в цифровом пространстве. Цифровая социализация обуславливает особый способ конструирования жизненного мира и специфический характер усвоения этических ценностей среди этих молодых людей. Социализация в цифровой среде также способствует развитию аномии. Развитие аномии у представителей поколения $\mathrm{Z}$ приводит к девиантному поведению, которое проявляется в немотивированной агрессии, оскорблению других участников коммуникации в цифровой среде. Наряду с аномией и девиацией цифровая социализация поколения $\mathrm{Z}$ характеризуется и противоположными тенденциями институционализации этики цифрового взаимодействия. Практики неэтичного поведения стимулируют появление в интернете дискуссий о рамках допустимого и недопустимого поведения. Этот стихийный дискурс цифровой этики крайне интересен как с теоретической, так и с практической точки зрения. Основываясь на естественных представлениях индивидов об этических нормах, возможно сформулировать кодекс этического поведения в цифровом пространстве. Подобный кодекс не будет обладать принудительной силой, однако сам факт его существования будет оказывать влияние на поведение индивидов. Изученные особенности поколения $\mathrm{Z}$ могут быть крайне полезны для совершенствования образования. Понимание специфики жизненного мира этих молодых людей позволит разрабатывать более интересные для них курсы и методики преподавания. Знание механизмов генезиса этических норм в цифровой среде может быть использовано для более эффективной трансляции молодежи социально конструктивных норм поведения и этических ценностей.

Ключевые слова: поколение Z, нормы, этика, аномия, цифровая среда

Библиографическая ссылка: Плетнев А.В. Генезис этических норм в цифровой среде как фактор аномии личности представителей поколения Z // Информационное общество: образование, наука, культура и технологии будущего. Выпуск 4 (Труды XXIII Международной объединенной научной конференции «Интернет и современное общество», IMS-2020 (сборник научных статей). - СПб: Университет ИТМО, 2020. С. 116-126. DOI: 10.17586/2587-8557-2020-4-116-126

\section{Введение}

В эпоху интенсивной сверхсовременности все большая доля межиндивидуального взаимодействия происходит в цифровой среде, что в свою очередь оказывает существенное влияние на социализацию молодого поколения. В этом отношении крайне интересно изучить генезис этических норм у представителей поколения $\mathrm{Z}$ под влиянием цифровой среды. Еще со времен Дюркгейма теоретики социологии при рассмотрении вопросов этики обращали внимание на наличие кризиса нормативно-ценного регулирования в обществе - аномии. 
$\mathrm{C}$ появлением нового поколения вопрос о соотношении процессов появления новых этических норм и эрозии существующих резко актуализировался, поскольку поколение Z это первое полностью цифровое поколение. Для изучения указанного исследовательского вопроса будут использоваться методы теоретического синтеза и реконцептуализации. Метод реконструкции концепции имеет огромный эвристический потенциал при применении классических социологических концепций для объяснения принципиально новых социальных явлений [4, с. 68]. Целью данного исследования является выявление сущности и особенностей процесса конструирования этических норм в жизненном мире поколения Z. Эпистемологической ориентацией исследования является интерпретативизм. Онтологическими ориентациями исследования являются номинализм и конструктивизм. Исследование выполнено в рамках индуктивной стратегии.

Для изучения генезиса этических норм у поколения $\mathrm{Z}$ необходимо понимание особенностей этого поколения. Исследования, посвящённые изучению поколений, опираются на работы Хоува и Штрауса [14, p. 97], которые предложили классификацию поколений и обосновали тезис о том, что каждое поколение имеет определенные культурные отличия. Впоследствии эта классификация поколений была дополнена поколением Z. K поколению Z по разным оценкам [5 с. 3350] относятся люди, родившиеся с 1995-1996 по 2004-2010. Изначально в книге Тулгана представители Z были определены как вторая волна миллениалов [25, р. 5], однако после его публикации в газете USA TODAY «High-maintenance Generation Z heads to work» в 2012 году поколение Z стало считаться самостоятельным явлением. Широкому распространению этого термина способствовала публикация [19] результатов маркетингового исследования поколения Z, проведенного компанией Sparks and Honey в 2014. В качестве синонимов понятия «Поколение Z» в научной и профессиональной литературе могут употребляться понятия «iGen» и «Post-Millennials». Пригодность западных классификаций поколений для изучения российского общества подтверждается актуальными эмпирическими исследованиями $[1,2]$. Более того поколение Z, которое благодаря интернету проходило социализацию под постоянным влиянием западного континента, больше, чем любое другое поколение похоже на своих западных сверстников. Это обстоятельство делает изучение особенностей этого поколения еще более интересным и позволяет в определенной степени экстраполировать наши выводы на другие страны.

\section{1. Характеристики поколения $Z$}

Особенности поколения $\mathrm{Z}$ во многом обусловлены особой структурой их жизненного мира. Чем моложе люди, тем в меньшей степени они склонны разделять события реального и виртуального мира. Постоянный обмен информацией между молодыми людьми обуславливает постоянное сопереживание событий жизни друг друга. Это порождает феномен ощущения себя участником события, даже если участие в этом событии заключалась только в восприятии информации о нем из интернета. Этот уникальный и не характерный для более старших поколений феномен формирования сопереживания заставляет представителей поколения $\mathrm{Z}$ формировать собственные сообщества и слабо контактировать с представителями более старших поколений.

Представители поколения $\mathrm{Z}$ выросли в информационно-коммуникативной среде, а потому с детства имеют неплохие навыки поиска и обработки информации. Сравнительные социологические данные свидетельствуют о том, что как российская, так и западная молодежь знает о понятии фейка и критически относятся к официальным СМИ [16]. Эти же навыки влияют и на их отношение к образованию, поскольку они не видят смысла заучивать те факты, которые легко можно найти с помощью Google. Поскольку поиск информации в интернете является быстрым, динамичным и легко доступным, это порождает у молодых людей отрицательное отношение к формальным образовательным институтам. 
С их точки зрения мало смысла записывать в академической аудитории ту информацию, которую при необходимости легко найти самостоятельно. При этом поколение $\mathrm{Z}$ ценит обучающие курсы, которые дают конкретные навыки, позволяющие начинать зарабатывать сразу, здесь и сейчас.

Выявленные нами особенности жизненного мира поколения Z способствуют тому, что эмоциональный и визуальный контент интернета имеет для них существенно больше значение, чем для представителей предыдущих поколений. Об этом наглядно свидетельствует обильное использование в социальных сетях смайлов, эмодзи и других графических инструментов, выражающих эмоциональное отношение. Содержательный текст в интернете зачастую сопровождается изображениями, иногда музыкой, что создает некую целостную, синестезическую картину.

В целом конструирование смыслов жизненного мира для поколения Z является совместным процессом, который протекает одновременно в реальном и виртуальном мире. По сути «ключевая отличительная особенность нового поколения заключается в том, что они не видят разницы между жизнью в сети и вне ее. Появление этой особенности поколения $\mathrm{Z}$ обусловлено феноменом нового вида взаимодействия, который объединяет мир физический и виртуальный, его определяют как phygital взаимодействие» [6, с.34]. Эта особенность представляет большой интерес, поскольку сильно отличает поколение Z от всех предшествующих поколений. Другой, не менее интересной особенностью, является то, что совместное конструирование смыслов в цифровом пространстве приобретает форму текста и это открывает принципиально новые возможности для исследователей. Прежде всего это касается этнометодологии, которая изучает ежедневное рутинное взаимодействие [17, p. 82]. С этнометодологической точки зрения интернет становится крайне перспективной возможностью изучения повседневности, поскольку в этом случае влияние исследователя на результаты исследования полностью исключено. Для нашего исследования интерес представляет конструирование в интернете понятий этичного и неэтичного, которые являются основой для социальных практик.

Интернет становится пространством трансляции ценностей и опыта от одного индивида к другому. В итоге личность представителя поколения $\mathrm{Z}$ является более гибкой, многогранной, чем у представителей старших поколений. Представитель поколения Z определяет себя скорее ситуативно, чем раз и навсегда однозначно. Грани его личности могут меняться в зависимости от влияния социального окружения и обстоятельств.

Крайне важным фактором, сильно влияющим на социализацию поколения Z, является феномен цифрового неравенства. Речь идет не только о демонстрации традиционной стратификации в цифровой среде, но и о принципиально новых явлениях. Также цифровое неравенство проявляется в обладании молодыми людьми дорогой цифровой техникой. К примеру, в социальных сетях значки могут указывать, что пользователь заходил или отправлял сообщения с техники Apple, находящейся в верхнем ценовом сегменте. Однако наиболее деструктивной формой цифрового неравенства является трансляция в цифровой среде практик символического потребления. Символическое потребление подразумевает приобретение дорогих, не нужных, однако подчеркивающих статус обладателя вещей. Такая модель потребления превращает даже обеспеченного индивида в постоянно нуждающегося, сверхнового бедного [3, с.24]. Цифровое пространство активно используется поколением $\mathrm{Z}$ для демонстрации статусного потребления. Даже посетив хороший ресторан, индивид, с мышлением сверхнового бедного, вероятно сфотографирует еду и выложит фотографию в Instagram. Без публичной демонстрации потребления прием пищи с его точки зрения превращается в пустую трату денег. Постоянная демонстрация символического потребления наиболее успешными представителями поколения $\mathrm{Z}$ вызывает у менее обеспеченных чувства раздражения и несправедливости. В итоге ощущение цифрового неравенства вызывает у молодых людей агрессию, и эта проблема напрямую связана с вопросами этики. 
Результатом социализации поколения $\mathrm{Z}$ в цифровом пространстве является их наилучшая приспособленность к жизни в современном обществе. Если предшествующим поколениям приходилось осваивать цифровую среду и её закономерности, то представители $\mathrm{Z}$ родились в ней и чувствуют там себя «как рыба в воде». Марк Пренски удачно концептуализировал это явление, назвав поколение $Z$ «цифровыми аборигенами» [22, р.1]. При этом необходимо понимать, что лучшая адаптация этих молодых людей заключается не только во владении цифровыми технологиями и знании языка цифрового общества, но и в лучшей приспособленности к условиям современной экономики, которая отличается нестабильностью, распространением практик удалённой работы, быстрой сменой трендов, а также необходимостью постоянно отслеживать огромные потоки информации.

Прекрасная адаптация поколения Z к современному обществу порождает и новые этические проблемы. К традиционному конфликту отцов и детей добавляется то, что можно назвать парадоксом осведомлённости. Если на протяжении всей истории младшие поколения получали знания от старших, то поколение $\mathrm{Z}$ само способно рассказать старшим много нового об особенностях цифрового общества и современной экономики. Как отметил исследователь цифровой социализации Д. Тапскотт, «впервые в истории дети более способны, осведомлены и грамотны, чем их родители в области инноваций, играющих центральную роль в обществе. Это достигается за счет использования цифровых медиа, которые „сетевое поколение“ продолжит разрабатывать и включать в культуру всего общества. Бэби-бумеры остались позади. Теперь эти дети учатся, играют, общаются, работают и строят общественные взаимоотношения иначе, чем их родители. Они - движущая сила грядущей социальной трансформации» [24, p.2]. Эта парадоксальная ситуация приводит к сильному межпоколенческому разрыву и в результате представители поколение $\mathrm{Z}$ предпочитают общаться в своей среде. Подобное обособление поколения $\mathrm{Z}$ затрудняет усвоение ими общепринятых норм и ценностей, в том числе и этических. Следует отметить, что старшие поколения во все времена были склонны критиковать молодых и их новую моду. В случае поколения Z эта тенденция выражена ещё сильнее, поскольку цифровые технологии породили много специфических особенностей их поведения. Чрезмерную критику молодёжи можно обнаружить даже в научных публикациях. Значительная часть научных статей о цифровом поколении посвящена клиповому мышлению, дезадаптации молодёжи и прочим негативным феноменам. Эту ситуацию хорошо описала Литкотт-Хаймс, которая была деканом Стенфордского университета и провела масштабное исследование поколения Z: «Мы видим негатив в том, что они не выходят на улицу, не могут смотреть людям в глаза, не прикладывают усилия, чтобы позвонить по телефону. Существует много недостатков этого поколения, которые демонстрируют нам социальные медиа, но есть и очевидные положительные стороны» [18, p. 196].

\section{2. Аномия в среде молодого поколения}

Противоположной тенденцией, затрудняющий генезис социальных норм, является развитие ценностного и нормативного кризиса - аномии. Начиная с конца XX века, многочисленные кросс-культурные исследования свидетельствуют о росте её уровня $[19,23]$, что приводит к ослаблению нормативного регулирования и противоречивости самих нормативных требований. И хотя эмпирические исследования аномии начались ещё в XIX веке, период конца XX века - начало XXI стал временем возрождение интереса к аномии. В настоящий момент мы можем констатировать не только увеличение уровня аномии, но и её качественное изменение. Наличие аномии в обществе стало для социологического сообщества нормой также, как и вызываемые ею девиантное поведение и повышенный уровень преступности. Состоянию аномии в наибольшей степени подвержены молодые люди, поскольку у них еще не сформировались 
твёрдые ценностные убеждения. Для нашего исследования наибольший интерес представляет та аномия, которая возникает в результате влияния цифровой среды.

Особенностью коммуникации в цифровой среде является мгновенная передача информации в любую точку мира, что приводит к свободному общению представителей всех культур. Однако необходимо учитывать, что разные культуры имеют различные, а иногда и взаимоисключающие ценностные основания. Это приводит к тому, что на социализирующегося представителя поколения $\mathrm{Z}$ оказывают влияние ценности нескольких культур и это может привести молодого человека к ценностной дезориентации - аномии. Вопрос об особенностях аномии, возникающей под влиянием цифровой коммуникации, не изучен и обладает характеристиками реальной научной новизны. К тому же в русскоязычной литературе при рассмотрении аномии её изучают только как социальный феномен и не учитывают личностные аспекты аномии. Роберт Агнию обосновал, что на уровне личности аномия является не просто отражением социального процесса, а самостоятельным, многоаспектным, социально-психологическим феноменом, который может быть вызван разными причинами [10]. В таком понимании аномия прежде всего кризис личности. Аномия в среде поколения $\mathrm{Z}$ приводит к трудностям в социализации и возникновению девиантного поведения. Взаимосвязь девиации и аномии, которая была обоснована ещё Дюркгеймом, в среде поколения $Z$ проявляется в развитии девиантных практик. Наиболее показательной из них является практика «хейта», когда идентифицировавший себя пользователь подвергается травли и оскорблениям со стороны анонимных пользователей. Практики хейта стали частью культуры общения в интернете и воспринимаются поколением Z как вариант нормального поведения. Однако частью пользователей такие практики осуждаются, что приводит к стихийному обсуждению допустимых и не допустимых с этической точки зрения вариантов поведения. Пользователи, которые настаивают на недопустимости хейта, особенно анонимного, предлагают соблюдать в интернете те же правила, что и при реальном общении, и полагают, что анонимные оскорбления являются следствием психологических проблем оскорбляющих.

Стихийные дискуссии, возникающие в цифровом пространстве при обсуждении допустимых моделей поведения, являются естественной основой для создания этического кодекса поведения в интернете. Очевидным преимуществом подобного кодекса является то, что он не создан искусственно, а, напротив, является результатом обобщения реально существующих социальных практик. Разумеется, этический кодекс - это не закон, и он не является обязательным для исполнения. Однако само существование такого документа определённо будет оказывать влияние на поведение индивидов в цифровом пространстве.

Предложенная стратегия выстраивания цифровой этики снизу, от микроуровня социального взаимодействия, крайне актуальна в настоящее время. По сути, «современное общество находится на начальной стадии понимания виртуальной реальности» [7, с. 172]. Объединение мира в единое цифровое пространство не только ставит перед нами новые этические вызовы, но и способно «стать исходной точкой поиска общих этических принципов на основе сохранения, интерпретации и применения особенностей отдельных культур» [9, с.221]. Единое цифровое пространство, по сути, означает формирование единой мировой культуры. Эта культура основана на использовании английского языка и включает единые универсальные культурные элементы: мемы, смайлы, особые понятия и прочее.

\section{3. Модели образования для поколения $\mathrm{Z}$}

В целом результаты проведенного исследования позволяют сформировать эффективные стратегии образования для поколения Z. Целью указанных стратегий является передача молодому поколению социально конструктивных ценностей и стимулирования в молодежной среде интереса к самостоятельному, творческому 
самообразованию. Современное образование для этой группы должно представлять собой реально-виртуальное взаимодействие по совместному освоению знания. Только такой образовательный процесс по-настоящему заинтересует представителей поколения Z и может способствовать их социализации и привитию им необходимых ценностей. Определённые усилия научного и педагогического сообщества в этом направлении можно наблюдать уже сейчас [21]. Признаком интуитивного понимания преподавателями особенностей нового поколения можно считать также и тенденции к демократизации и диалогизации взаимодействия со студентами [12], все большему использованию сократического метода, который предполагает формулировку знания самим обучаемым, а не получение его в готовом виде от преподавателя. Однако наибольшего эффекта педагогической деятельности можно добиться, выстраивая образовательный процесс с позиции поколения $\mathrm{Z}$, исходя из описанных особенностей конструирования им социальной реальности.

Здесь следует отметить, что хотя феномен реально-виртуального совместного конструирования знаний является принципиально новым и свойственен только для поколения $\mathrm{Z}$ и предположительно для последующего поколения $\mathrm{A}$, аналогичный феномен можно обнаружить в глубокой древности. Это очень похоже на сократический метод, который подразумевает, что обучаемый самостоятельно находит ответы и приходит к выводам в процессе дискуссии, а обучающий только направляет его мышление своими вопросами и стимулирует у него интерес к наукам [13, p. 27]. Сократический метод является исторически первым методом образования, самым эффективным и на сегодняшний день используется только элитными вузами. Во времена промышленной революции необходимость давать образование большой массе людей, по сути, привело к отказу от этого индивидуализированного подхода. Предлагаемая же стратегия совместного виртуально-реального конструирования знания в некотором смысле возвращает нас к истокам.

Предложенная нами модель образования не только приведет к лучшему получению знаний, но и будет способствовать преодолению межпоколенческого разрыва. Усвоение молодым поколением этических ценностей в конечном счёте стимулирует преодоление аномии. Это очень важный аспект образования, поскольку укрепление в обществе этических норм и ценностей обратно пропорционально аномии, а значит и вызываемых ею преступности и девиации. Одним из главных синонимов аномии в криминологической литературе является бесцельность. Появлению этой бесцельности способствует контент интернета и содержание массовой культуры. Глубокий интерес к образованию способен помочь молодым людям стать лучшими специалистами, пробудить в них интерес к научным исследованиям и в целом получить более осмысленную жизнь. Таким образом внедрение новой образовательной парадигмы - это не только теоретически значимый, но и практически ценный вопрос, который способен привести к далеко идущим последствиям. Это означает, что созданная предложенным нами способом образовательная стратегия универсальна и может применяться в любой стране мира.

Важным аспектом совершенствования образования, ориентированного на поколение $\mathrm{Z}$, может стать учёт влияния неформальных образовательных сообществ. Это явление широко распространено в цифровом пространстве и неформальные образовательные сообщества мы можем определить как глобальные сообщества в цифровой среде, объединённые специфическими образовательными интересами. Подобные сообщества могут быть в большей или меньшей степени институционализированы. Предметом интереса для таких сообществ могут быть естественные науки, история, палеонтология, разнообразные образовательные видео и многое другое.

Одним из крупнейших неформальных образовательных сообществ является сообщество TED (technology, entertainment, design), организованное частным некоммерческим образовательным фондом. Не связанное с формальным образованием, это сообщество проводит конференции, выпускает обучающее видео, выдаёт премии и вносит 
значительный вклад в развитие образования и науки. В России, Казахстане, Белоруссии и многих других странах существуют отделения этого сообщества, которые переводят образовательные материалы на национальные языки, а также способствует развитию образования. Сделанные в развлекательной манере анимационные образовательные ролики этого сообщества вызывают у представителей поколения $\mathrm{Z}$ огромный интерес. Подобный интерес со стороны аудитории, к сожалению, не вызывают образовательные материалы, которые предлагают формальные образовательные институты.

В социальных сетях и вообще в цифровой среде можно обнаружить также и множество неформальных, неинституционализированных сообществ, численность членов которых может достигать нескольких сотен тысяч, а то и миллионов пользователей. Подобные сообщества предлагают видеолекции на разные темы, изображения, аудиофайлы, книги в PDF формате и дискуссии в обсуждениях. Изучив сообщества, посвящённые религии, истории, политологии, можно обнаружить достаточно профессиональные обсуждения вопросов, в которых участвует люди, которым не нужно сдавать экзамен для получения кого-либо формального статуса. Всё изложенное означает, что неформальные образовательные сообщества создали весьма эффективные образовательные практики, которые могли бы быть с успехом применены и в рамках формального образования. Также крайне перспективной представляется идея интеграции формальных и неформальных образовательных сообществ. При изучении любого предмета в университете можно рекомендовать студентам участвовать в неформальном образовательном сообществе по соответствующей теме, снабжать это сообщество учебными материалами, а также брать учебные материалы из него. Эта идея является перспективной, поскольку неформальные образовательные сообщества всегда ориентированы на молодежь, состоят из молодёжи и в них сами молодые люди подбирают наиболее интересные для себя материалы.

Предметом внимания неинституционализированных неформальных образовательных сообществ зачастую являются и вопросы этики. В цифровом пространстве можно встретить обсуждение должного поведения с точки зрения определённых религий или философских систем. Наиболее ярким примером вклада неформальных сообществ в обсуждение вопросов этики является перевод на русский язык курса "Справедливость", прочитанного профессор Майклом Сэнделом в Гарвардском университете. Перевод был выполнен сообществом "The Lectures from Top Universities " в социальной сети Вконтакте, которое привлекло для этой цели 20 добровольцев. Это очень серьезный курс, в котором рассматриваются фундаментальные этические вопросы. Следует отметить, что даже престижные университеты редко занимаются переводом гарвардских и стенфордских лекций для знакомства с ними русскоязычной аудитории. Это является существенным недостатком, поскольку "особенностью российской педагогики следует признать слабую осведомлённость в области зарубежных теоретических концепций и отсутствие попыток их применения в отечественной практике"[8, с.192-193]. Не менее отрадным является тот факт, что работа по переводу курса "Справедливость" была проделана представителями того самого поколения Z, которое испытывает проблему межпоколенческого разрыва и нуждается в усвоении этических норм и ценностей.

\section{Заключение}

По результатам представленного исследования можно сделать вывод, что западные классификации поколений подходят для изучения российского общества и существенные особенности поколения Z одинаковы как для России, так и для Запада. Социализация в цифровой среде сформировала у поколения $\mathrm{Z}$ специфический способ конструирования жизненного мира, при котором виртуальное взаимодействие воспринимается также, как и реальное. Выявление особенностей конструирования жизненного мира представителями поколения $\mathrm{Z}$ является главным результатом представленной работы, поскольку эти особенности позволяют лучше понимать причины отличия поколения $\mathrm{Z}$ от старших 
поколений. Результаты данной работы интересны как для теории, поскольку они раскрывают неизученные особенности поколения Z, так и для практики, так как они могут послужить основой для разработки эффективных образовательных программ. Эффективные программы обучения способны не только заинтересовать молодых людей знанием и способствовать усвоению материала, но и привить им этические ценности, а также практики этичного взаимодействия в виртуальном пространстве. Огромным потенциалом в деле совершенствования образования обладают неформальные, неинституционализирванные образовательные сообщества. Наиболее эффективной моделью построения образования для поколения $\mathrm{Z}$ является реально-виртуальное совместное конструирование знания на основе сократического метода. Важной частью этого образования станет трансляция молодому поколению этических ценностей. Учет роли этических ценностей в построении образования не только приведёт к более этичным практикам поведения среди поколения Z, но и будет способствовать преодолению аномии. Снижение уровня аномии способно крайне существенно снизить количество проявлений девиантного и преступного поведения.

\section{Литература}

[1] Волкова Н.В., Чикер В.А. Особенности карьерной мотивации в контексте теории поколений: результаты эмпирического исследования // Вестник Санкт-Петербургского университета. Менеджмент. 2016. № 4. С. 79-105.

[2] Зверева Е.А. Особенности медиапотребления "поколения у" и "поколения z" // Социально-гуманитарные знания. 2018. № 8. С. 205-216.

[3] Иванов Д.В. Глэм-капитализм: общество потребления в XXI в. // Журнал социологии и социальной антропологии. 2011. Т. 14, № 5. С. 9-28.

[4] Игнатьева О.А. Реконструкция концепции власти М. Вебера и ее методологическое значение // Мир политики и социологии. 2012. № 2. С. 67-73.

[5] Малетин С.С. Особенности потребительского поведения поколения Z // Российское предпринимательство. 2017. Т. 18, № 21. С. 3347-3360.

[6] Мамина Р.И., Толстикова И.И. Phygital поколение в условиях свободной глобальной коммуникации // International Journal of Open Information Technologies. 2020. T. 8, № 1. C. $34-41$.

[7] Осинцева Н.В., Муратова И.А. Трансформация этических ценностей в условиях развития цифровых технологий // Манускрипт. 2020. Т. 13, № 1. С. 171-175.

[8] Плетнев А.В. Развитие социальной аномии как фактор изменения педагогических практик в условиях виртуализирующегося общества // Вестник Санкт-Петербургского университета МВД России. 2018. № 3 (79). С. 190-193.

[9] Толстикова И.И. Инфоэтика свободной глобальной коммуникации // Информационное общество: образование, наука, культура и технологии будущего. 2018. № 2. С. 217-222.

[10] Agnew R. Building on the Foundation of General Strain Theory: Specifying the Types of Strain Most Likely to Lead to Crime and Delinquency // Journal of Research in Crime and Delinquency. 2001. Vol. 38, Iss. 4. P. 319-361.

[11]Ballantine J. H., Spade J. Z. Schools and Society: A Sociological Approach to Education. New York. SAGE Publications, Inc., 2014.

[12] Benincasa L. Democratic education and the 'strategy of material obstacles': a pedagogical approach to the enforcement of traffic rules in a Greek town // Ethnography and Education. 2016. Vol. 11, №. 1. P. 1-20.

[13] Crawford C. M., Hardy S. L. Dynamic Principles of Professional Development: Essential Elements of Effective Teacher Preparation. Maryland. Rowman, 2017.

[14] Strauss W., Howe N. The Fourth Turning: An American Prophecy. New York. Broadway Books, 1997. 
[15]Hughes L. A., Schaible L. M., Gibbs B. R. Economic Dominance, the "American Dream," and Homicide: A Cross-National Test of Institutional Anomie Theory // Sociological Inquiry. 2014. Vol. 85, Iss. 1. P. 100-128.

[16]Laruelle M., Beyond Putin: Russia's Generations Y and Z // PONARS Eurasia Policy Memo. 2019. №. 579. P. 1 - 6.

[17] Lehn D. V. Harold Garfinkel: The Creation and Development of Ethnomethodology. New York. Routledge, 2014.

[18] Lythcott-Haims J. How to raise an adult. Spokane. Griffin, 2016.

[19] Meet Generation Z: Forget Everything You Learned About Millennials URL: https://www.slideshare.net/sparksandhoney/generation-z-final-june-17/5-A_generation_with disposable_income5Gen (дата обращения: 22.03.2020).

[20] Messner S. F., Rosenfeld R. Crime and the American Dream, 5th Edition. Andover. Wadsworth, 2013.

[21] Murad, R., Hussin, S., Yusof, R., Miserom, S. F., \& Yaacob, M. H. A Conceptual Foundation for Smart Education Driven by Gen Z. // International Journal of Academic Research in Business and Social Sciences. 2019. Vol. 9, № 5. P. 1022-1029.

[22] Prensky M. Digital Natives, Digital Immigrants Part 1 // On the Horizon. Vol. 9, №5. P. 1-6.

[23] Teymoori A., Jetten J., Bastian B., Ariyanto A., Autin F., Ayub N., et al. Revisiting the Measurement of Anomie // PLoS ONE. Vol. 7, № 11. P. 1-27.

[24] Tapscott D. Grown Up Digital: How the Net Generation is Changing Your World. New York. McGraw-Hill Education, 2008.

[25] Tulgan B. Not Everyone Gets A Trophy: How to Manage the Millennials. 18-th edition. San Francisco. JosseyBass, 2016.

\title{
Genesis of Ethical Standards in the Digital Environment as a Factor in the Anomie of the Personality of Representatives of Generation $Z$
}

\author{
A.V. Pletnev
}

\section{$\mathrm{SPb}$ University of Internal Affairs Ministry}

The socialization of representatives of the $\mathrm{Z}$ generation is largely going on in the digital space. Digital socialization determines a special way of constructing the life world and the specific nature of assimilation of ethical values among these young people. Socialization in a digital environment also contributes to the development of anomie. The development of anomie among representatives of generation $\mathrm{Z}$ leads to deviant behavior, which manifests itself in unmotivated aggression, an insult to other participants in communication in the digital environment. Along with anomie and deviation, the digital socialization of Generation $\mathrm{Z}$ is also characterized by opposing trends in institutionalizing the ethics of digital interaction. Practices of unethical behavior stimulate the appearance on the Internet of discussions about the framework of permissible and unacceptable behavior. This spontaneous discourse of digital ethics is extremely interesting from both a theoretical and a practical point of view. Based on the natural views of individuals about ethical standards, it is possible to formulate a code of ethical behavior in digital space. Such a code would not be coercive, but the very fact of its existence would influence the behavior of individuals. The studied features of generation $\mathrm{Z}$ can be extremely useful for improving education. Understanding the specifics of the life world of these young people will allow them to develop more interesting courses and teaching methods. Knowledge of the mechanisms of the genesis of ethical norms in the digital environment can be used to more effectively transmit youth socially constructive norms of behavior and ethical values.

Keywords: generation Z, norms, ethics, anomie, digital environment 
Reference for citation: Pletnev A.V. Genesis of ethical standards in the digital environment as a factor in the anomie of the personality of representatives of generation Z // Information Society: Education, Science, Culture and Technologies of the Future. Vol. 4 (Proceedings of the XXII International JointScientific Conference «Internet and Modern Society», IMS-2020, St. Petersburg, June 17-20, 2020). - St. Petersburg: ITMO University, 2020. P. 116 - 126. DOI: $10.17586 / 2587-8557-2020-4-116-126$

\section{Reference}

[1] Volkova N.V., CHiker V.A. Osobennosti kar'ernoj motivacii v kontekste teorii pokolenij: rezul'taty empiricheskogo issledovaniya // Vestnik Sankt-Peterburgskogo universiteta. Menedzhment. 2016. № 4. S. 79-105. (in Russian).

[2] Zvereva E.A. Osobennosti mediapotrebleniya "pokoleniya y" i "pokoleniya z" // Social'nogumanitarnye znaniya. 2018. № 8. S. 205-216. (in Russian).

[3] Ivanov D.V. Glem-kapitalizm: obshchestvo potrebleniya v XXI v. // ZHurnal sociologii i social'noj antropologii. 2011. T. 14, № 5. S. 9-28. (in Russian).

[4] Ignat'eva O.A. Rekonstrukciya koncepcii vlasti M. Vebera $\mathrm{i}$ ee metodologicheskoe znachenie // Mir politiki i sociologii. 2012. № 2. S. 67-73. (in Russian).

[5] Maletin S.S. Osobennosti potrebitel'skogo povedeniya pokoleniya Z // Rossijskoe predprinimatel'stvo. 2017. T. 18, № 21. S. 3347-3360. (in Russian).

[6] Mamina R.I., Tolstikova I.I. Phygital pokolenie v usloviyah svobodnoj global'noj kommunikacii // International Journal of Open Information Technologies. 2020. T. 8, № 1. S. 34-41. (in Russian).

[7] Osinceva N.V., Muratova I.A. Transformaciya eticheskih cennostej v usloviyah razvitiya cifrovyh tekhnologij // Manuskript. 2020. T. 13, № 1. S. 171-175. (in Russian).

[8] Pletnev A.V. Razvitie social'noj anomii kak faktor izmeneniya pedagogicheskih praktik v usloviyah virtualiziruyushchegosya obshchestva // Vestnik Sankt-Peterburgskogo universiteta MVD Rossii. 2018. № 3 (79). S. 190-193. (in Russian).

[9] Tolstikova I.I. Infoetika svobodnoj global'noj kommunikacii // Informacionnoe obshchestvo: obrazovanie, nauka, kul'tura i tekhnologii budushchego. 2018. № 2. S. 217-222. (in Russian).

[10] Agnew R. Building on the Foundation of General Strain Theory: Specifying the Types of Strain Most Likely to Lead to Crime and Delinquency // Journal of Research in Crime and Delinquency. 2001. Vol. 38, Iss. 4. P. 319-361.

[11]Ballantine J. H., Spade J. Z. Schools and Society: A Sociological Approach to Education. New York. SAGE Publications, Inc., 2014.

[12] Benincasa L. Democratic education and the 'strategy of material obstacles': a pedagogical approach to the enforcement of traffic rules in a Greek town // Ethnography and Education. 2016. Vol. 11, №. 1. P. 1-20.

[13] Crawford C. M., Hardy S. L. Dynamic Principles of Professional Development: Essential Elements of Effective Teacher Preparation. Maryland. Rowman, 2017.

[14] Strauss W., Howe N. The Fourth Turning: An American Prophecy. New York. Broadway Books, 1997.

[15]Hughes L. A., Schaible L. M., Gibbs B. R. Economic Dominance, the "American Dream," and Homicide: A Cross-National Test of Institutional Anomie Theory // Sociological Inquiry. 2014. Vol. 85, Iss. 1. P. 100-128.

[16]Laruelle M., Beyond Putin: Russia's Generations Y and Z // PONARS Eurasia Policy Memo. 2019. №. 579. P. 1- 6.

[17]Lehn D. V. Harold Garfinkel: The Creation and Development of Ethnomethodology. New York. Routledge, 2014.

[18] Lythcott-Haims J. How to raise an adult. Spokane. Griffin, 2016. 
[19] Meet Generation Z: Forget Everything You Learned About Millennials URL: https://www.slideshare.net/sparksandhoney/generation-z-final-june-17/5-

A_generation_with_disposable_income5Gen (data obrashcheniya: 22.03.2020).

[20] Messner S. F., Rosenfeld R. Crime and the American Dream, 5th Edition. Andover. Wadsworth, 2013.

[21] Murad, R., Hussin, S., Yusof, R., Miserom, S. F., \& Yaacob, M. H. A Conceptual Foundation for Smart Education Driven by Gen Z. // International Journal of Academic Research in Business and Social Sciences. 2019. Vol. 9, № 5. P. 1022-1029.

[22] Prensky M. Digital Natives, Digital Immigrants Part 1 // On the Horizon. Vol. 9, №5. P. 1-6.

[23] Teymoori A., Jetten J., Bastian B., Ariyanto A., Autin F., Ayub N., et al. Revisiting the Measurement of Anomie // PLoS ONE. Vol. 7, № 11. P. 1-27.

[24] Tapscott D. Grown Up Digital: How the Net Generation is Changing Your World. New York. McGraw-Hill Education, 2008.

[25] Tulgan B. Not Everyone Gets A Trophy: How to Manage the Millennials. 18-th edition. San Francisco. JosseyBass, 2016. 